\title{
Long-term Measurements of Nighttime LF Radio Wave Reflection Heights over Central Europe
}

\author{
C. Jacobi ${ }^{1}$ and D. Kürschner ${ }^{2}$ \\ ${ }^{1}$ Institute for Meteorology, University of Leipzig, Stephanstr. 3, 04103 Leipzig, Germany \\ ${ }^{2}$ Institute for Geophysics and Geology, University of Leipzig, Collm Observatory, 04779 Wermsdorf, Germany
}

\begin{abstract}
The nighttime ionospheric absolute reflection height of low-frequency (LF) radio waves at oblique incidence has been measured continuously since late 1982 using $1.8 \mathrm{kHz}$ sideband phase comparisons between the sky wave and the ground wave of a commercial $177 \mathrm{kHz}$ LF transmitter. The dataset allows the analysis of long-term trends and other regular variations of the reflection height. Beside the clear signal of the 11-year solar cycle a quasi-biennial oscillation is visible in LF reflection heights, which is correlated to the equatorial stratospheric wind field. A long-term decreasing reflection height trend is found, confirming results from other measurements and theoretical estimations. The results can be interpreted as a long-term decrease of the height levels of fixed electron density in the lower E region, reflecting a long-term cooling trend of the middle atmosphere.
\end{abstract}

\section{Introduction}

It has been known for a long time that the middle and upper atmosphere may serve as an indicator for climate variability. For instance, it has been shown that in general the increase of greenhouse gases results in a cooling of the stratosphere (Ramaswamy et al., 2001) and mesosphere (Beig et al., 2003). Considering the upper mesosphere/lower thermosphere region, this leads to a descent of layers of constant pressure, which may be monitored using radio wave reflection heights, which are connected with altitudes of constant electron density that in turn are controlled by the pressure profile (von Cossart and Taubenheim, 1987; Bremer and Berger, 2002).

At shorter time scales, one of the most prominent neutral middle atmospheric circulation patterns is the equatorial quasi-biennial oscillation (QBO, e.g. Naujokat, 1986). It influences the mid- and high-latitude middle atmosphere as well (Holton and Tan, 1980; Labitzke, 2004), so that, for

Correspondence to: C. Jacobi

(jacobi@uni-leipzig.de) example, during QBO west phases the winter stratospheric vortex is deeper and colder than during QBO east phases. The influence of the QBO on the upper atmosphere, however, is less clear. Jarvis (1997) found a QBO modulation of the semidiurnal tide expressed in ground geomagnetic variations. Jacobi et al. (1996), analysing Collm Central Europe lower thermosphere winds found that only the winter zonal prevailing winds are stronger during QBO west phase. This is in accordance with the stratospheric behaviour described by Holton and Tan (1980), but upper mesosphere wind measurements over Saskatoon, Canada, although revealing some biennial or quasi-biennial periodicity (Namboothiri et al., 1994), did not show a clear correspondence with the equatorial QBO. To conclude, the results on the QBO effect on the MLT region still appears to be inconclusive to a certain degree.

To investigate the long-term variability of the upper middle atmosphere, we analysed nighttime low-frequency (LF) radio wave absolute reflection heights. When interpreting these data, however, it has to be taken into account that these height variations show the signal of a mixture of different processes, namely changes of neutral atmosphere pressure level heights and changes in lower E-region ionisation. Therefore, the results have to be interpreted with care when conclusions about atmospheric variability should be drawn.

\section{Description of the measurements}

Low frequency $177 \mathrm{kHz}$ radio waves from a commercial radio transmitter are registered at Collm Observatory, Germany (distance to transmitter $170 \mathrm{~km}$ ). The virtual reflection heights $h^{\prime}$, referring to the reflection point at $52.1^{\circ} \mathrm{N}$, $13.2^{\circ} \mathrm{E}$, are estimated using measured travel time differences between the ground wave and the reflected sky wave through phase comparisons on sporadic oscillation bursts of the amplitude modulated LF radio wave in a small modulation frequency range around $1.8 \mathrm{kHz}$ (Kürschner et al., 1987). Because here we are primarily interested in a qualitative 


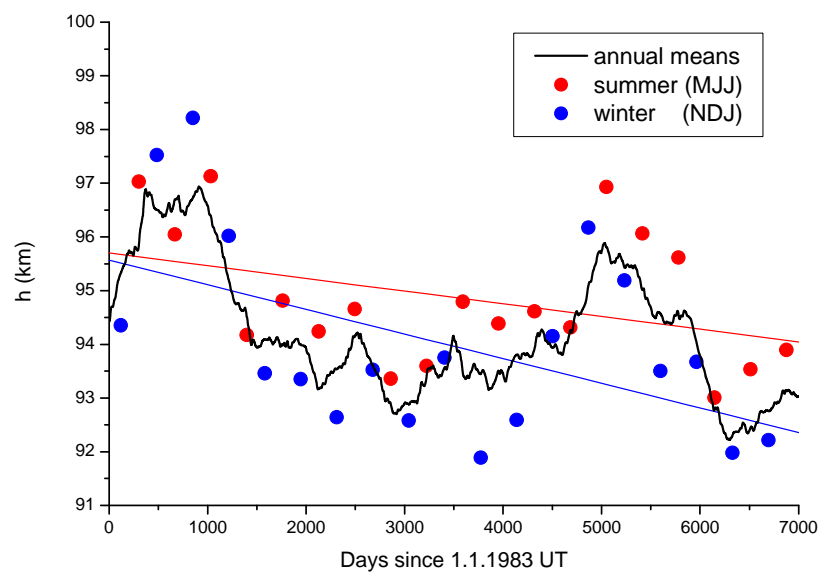

Fig. 1. Time series of annual mean virtual reflection heights (black line). Also given are seasonal (90 day) means for summer (MayJuly, red dots) and winter (November-January, blue dots).

analysis of heights, the original virtual heights are used here. For most part of the measurements, the retardation effect is small, as has been found from wave field calculations. Virtual reflection heights range between roughly $80 \mathrm{~km}$ during day and more than $100 \mathrm{~km}$ during nighttime for the ordinary component.

The reflection height measurements have started in September 1982 and are carried out continuously since then. During daylight hours, particularly in the summer months height measurements are not possible due to the strong Dregion absorption then. Therefore, and because the radio wave reflection height exhibits a strong diurnal variation, it is not possible to average over all measured height values of one day to derive daily mean heights. Therefore, a least squares fit was applied to detect the nighttime mean height and a semidiurnal variation:

$h^{\prime}(t)=h_{0}+a \cdot \sin \frac{2 \pi}{12 h} t+b \cdot \cos \frac{2 \pi}{12 h} t+\varepsilon$,

with $h_{0}$ as the daily mean, $\Delta h=\left(a^{2}+b^{2}\right)^{1 / 2}$ as the 12-h oscillation amplitude and $\varepsilon$ as indefinite height variations. Each regression analysis was applied to 15 days of half-hourly mean $h^{\prime}$ values, and the resulting mean nighttime height was attributed to the centre of the respective time window. The window then was shifted by one day, and the procedure was repeated.

The $\mathrm{h}_{0}$ time series presented here differs somewhat from the phase-height measurements presented by von Cossart and Taubenheim (1987) or Bremer and Berger (2002) in such a way, that we measure continuously during the night, while phase-height measurements are taken once a day at daytime and refer to a constant zenith angle. In addition the transmitter distance for the phase-height measurements was much longer. Therefore our average height is found at the lower nighttime E-region well above $90 \mathrm{~km}$, while the phase-height measurements show reflection heights at about $82 \mathrm{~km}$ in the D-region.

\section{Long-term trends}

The time series of reflection heights is shown in Fig. 1. The data are 1-year mean values, shifted by 1 day. Also shown are seasonal (90 day) means for summer and winter. Besides a decadal variation, a clear long-term decrease is visible. Linear fits are added. It can be seen that the trends are negative. The decrease amounts to $-90 \pm 40 \mathrm{~m} / \mathrm{yr}$ in summer, and $-170 \pm 60 \mathrm{~m} / \mathrm{yr}$ in winter. During equinoxes (not shown here) the respective values are $-110 \pm 40 \mathrm{~m} / \mathrm{yr}$ (spring) and $-100 \pm 45 \mathrm{~m} / \mathrm{yr}$ (autumn). Hence, the decrease takes place in each season, with maximum values in winter. This is qualitatively in agreement with the results of Bremer and Berger (2002), who found stronger decrease in D-region reflection heights in December and January.

Note also that the estimated trend may slightly overestimate the real trend, since the begin and the end of the time series are not exactly in the same phase of the solar cycle. To remove this effect from the trend analyse we calculated a multiple linear regression analysis, including simultaneously the 11-year oscillation and a possible linear trend. This analysis revealed nearly the same values of annual height decrease.

If we assume that both composition and effective recombination coefficient remain constant during the time interval under consideration, we may assume that the reflection heights represent heights of constant pressure, so that, following Bremer and Berger (2002) we may calculate the mean temperature change through integrating the hydrostatic equation from a lower reference level to our reflection height for the past (i.e. 1983) and present (i.e. 2001) conditions:

$$
\int_{48 k m}^{z_{2}} \frac{1}{T} d z=\int_{48 k m-\Delta z_{1}}^{z_{1}-\Delta z_{2}} \frac{1}{T(z)-\Delta T} d z .
$$

We use the CIRA (Fleming et al., 1990) temperatures, upper reference levels of $z_{2}=95.5 \mathrm{~km}$ for summer and winter, $96 \mathrm{~km}$ for spring, and $94 \mathrm{~km}$ for autumn as "past" conditions, and the $\Delta z_{2}$ values given above. The change of reference height near $48 \mathrm{~km}$ was taken as $\Delta z_{1}=10 \mathrm{~m} / \mathrm{yr}$ after Taubenheim (1994). The resulting temperature trends are $0.93 \mathrm{~K} / \mathrm{yr}$ for winter, $0.57 \mathrm{~K} / \mathrm{yr}$ for spring, $0.47 \mathrm{~K} / \mathrm{yr}$ for summer, and $0.61 \mathrm{~K} / \mathrm{yr}$ for autumn. Comparing these data with those presented by Beig et al. (2003), we find that our results are not outside the variety of measurements, but the trends are stronger than the average of other methods.

Of course, our assumption of constant air composition and recombination coefficient are not realistic. Therefore, our derived trends are not more than a first rough estimate of temperature trends. While the assumption of constant composition may lead to an underestimation of trends (see Bremer and Berger, 2002), the influence of the solar cycle will lead to a potential overestimation of trends, because the beginning of the time series falls into solar minimum, while the end is near solar maximum. 


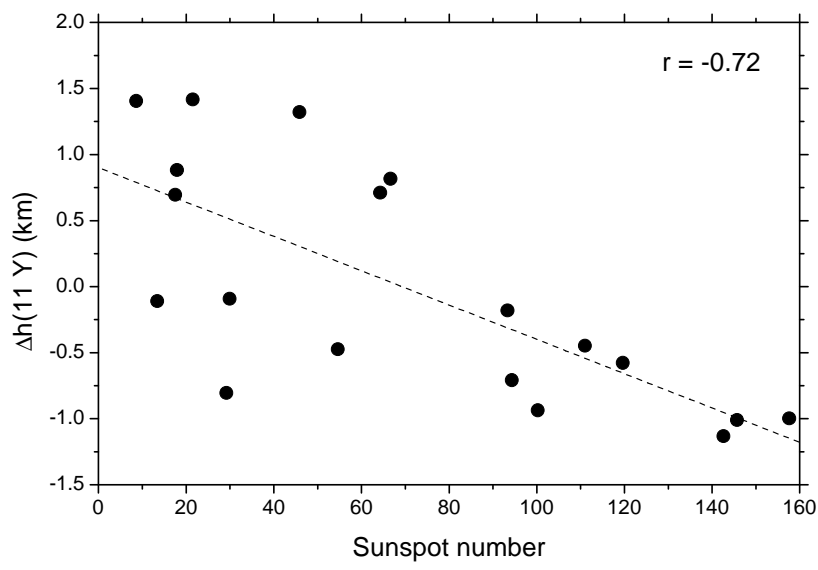

Fig. 2. Annual mean differences of the low-pass filtered winds (cutoff 4 yrs) vs. the annual mean sunspot number.

\section{Solar cycle}

To show variations in the period range of months to years, we applied transverse band-pass filters to the time series. Apart from the annual and semiannual cycle, an 11-year variation and the QBO effect appears to be the prominent features. To highlight the solar cycle dependence, in Fig. 2 the low-pass filtered $\mathrm{h}_{0}$ data are plotted vs. the annual mean sunspot numbers. The reflection heights are lower during solar maximum (see also Fig. 1) than during solar minimum, which is easily understandable from the stronger ionisation during times of high solar activity.

The amplitude of the 11-year oscillation amounts to about $1 \mathrm{~km}$, i.e. the difference between solar maximum and minimum is $2 \mathrm{~km}$. This is more than that has been given in literature (Entzian, 1967). However, we refer to a different height region than these results do. In addition, it is known that the neutral stratosphere and mesosphere exhibit a signal of the 11-year solar cycle as well (e.g., van Loon and Labitzke, 1990; Keckhut et al., 1995), which may contribute to the effect shown in Fig. 2. This means, on time scales of solar variability we cannot clearly distinguish between the solar effect through E-region ionisation and a possible atmospheric response.

\section{QBO}

In Fig. 3 the band-pass filtered reflection heights, with a resonant frequency of 2.2 years are shown together with the equatorial winds at $30-\mathrm{hPa}$ heights. The lengths of the cycles are varying from 22 to 32 months, with a mean length of 27 months. This is well within the ranges of the stratospheric QBO (Naujokat, 1986). It can be seen that for QBO West years in most cases the reflection heights are lower than those during QBO East years. This would fit to the concept of a cooler middle atmosphere during QBO West years, which is in correspondence with the stratospheric behaviour during winter (Holton and Tan, 1980).

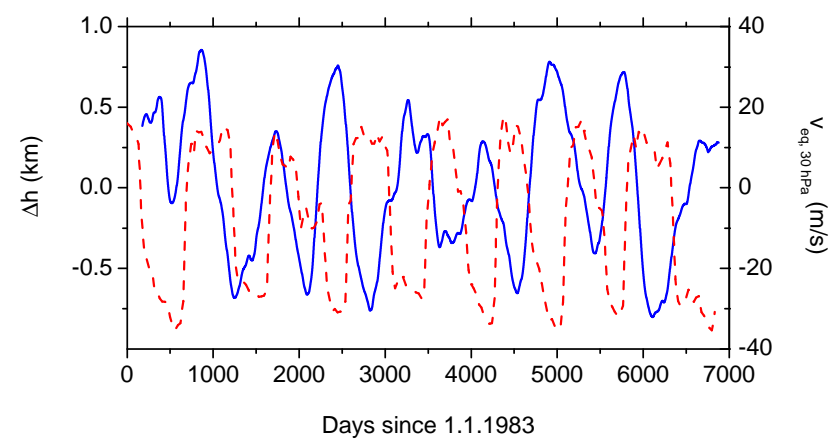

Fig. 3. Time series of band pass (2.2 years) filtered reflection heights (blue line, left axis), and equatorial winds at $30 \mathrm{hPa}$ (red dashed line, right axis).

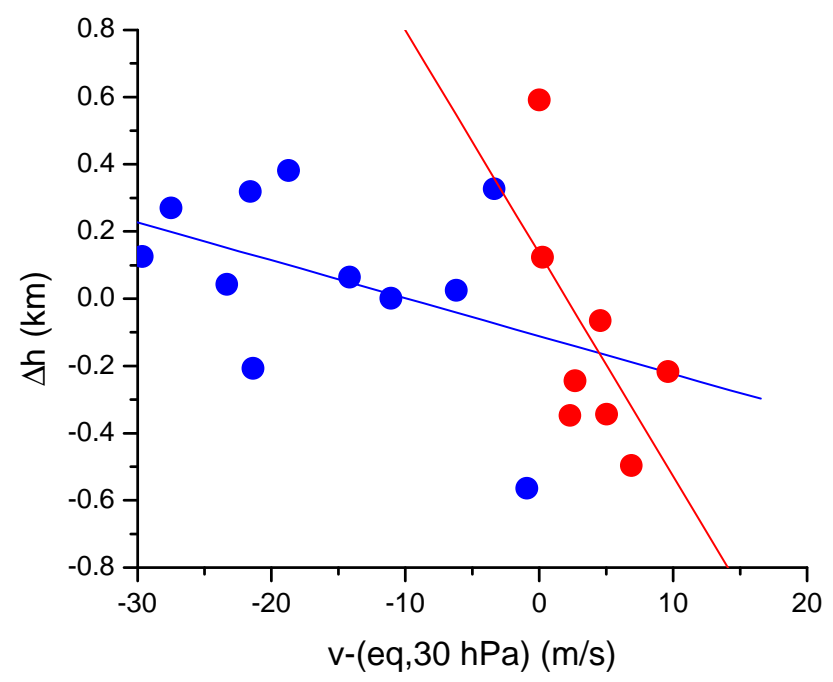

Fig. 4. Annual mean band pass (2.2 years) filtered reflection heights vs. equatorial winds at $30 \mathrm{hPa}$.

Reflection height differences vs. equatorial QBO are presented in Fig. 4. It can be seen from separate linear fits for QBO East and QBO West years, however, that for equatorial westerlies (and weak easterlies) there is a possible effect on the midlatitude lower ionosphere, but for QBO East years this effect is weak.

\section{Conclusions}

We have shown nighttime LF reflection heights measured at Collm, Germany. The long-term time series reveals a solar cycle, a long-term decreasing trend, and a QBO. While the influence of the 11-year solar cycle at least partly is obviously due to increasing radiation during solar maximum, the other effects are probably of atmospheric origin, connected with a long-term cooling of the mesosphere and the equatorial stratospheric circulation.

There has been a long debate about trends in ionospheric parameters as possible indicators for atmospheric 
variations (Bencze and Poor, 1996; Ulich and Turunen, 1997; Lastovicka and Bremer, 2004; Bremer, 2004). Our LF measurements may provide another piece of evidence that long-term cooling of the atmosphere, as well as interannual atmospheric variability, really changes the lower ionospheric regions. However, when interpreting ionospheric results in terms of atmospheric variability, care must be taken to distinguish between in situ ionospheric effects and influences from below.

Acknowledgements. This study has been supported by BMBF under grant 07ATF10 (MEDEC).

\section{References}

Beig, G., Keckhut, P., Lowe, R. P., Roble, R. G., Mlynczak, M. G., Scheer, J., Fomichev, V. I., Offermann, D., French, W. J. R., Shepherd, M. G., Semenov, A. I., Remsberg, E. E., She, C. Y., Lübken, F. J., Bremer, J., Clemesha, B. R., Stegman, J., Sigernes, F., and Fadnavis, S.: Review of mesospheric temperature trends, Rev. Geophys. 41, 1015, doi:10.1029/2002RG000121, 2003.

Bencze, P. and Poor, A.: On the effect of greenhouse gases in the upper atmosphere, Acta Geod. Geoph. Hung., 31, 439-444, 1996.

Bremer, J.: Investigations of long-term trends in the ionosphere with world-wide ionosonde observations, Adv. Radio Sci., 2, 253-258, 2004.

Bremer, J. and Berger, U.: Mesospheric temperature trends derived from ground-based LF phase-height observations at midlatitudes: comparison with model simulations, J. Atmos. SolarTerr. Phys., 64, 805-816, 2002.

Entzian, G.: Der Sonnenfleckenzyklus in der Elektronenkonzentration der D-Region, Kleinheubacher Berichte, 12, 309-313, 1967.

Fleming, E. L., Chandra, S., Barnett, J. J., and Corney, M.: Zonal mean temperature, pressure, zonal wind, and geopotential height as function of latitude, Adv. Space Res. 10 (12), 11-59, 1990.

Holton, J. R. and Tan, H.-C.: The influence of the equatorial quasibiennial oscillation on the global circulation at $50 \mathrm{mb}$, J. Atmos. Sci., 37, 2200-2208, 1980.

Jacobi, Ch., Schminder, R., and Kürschner, D.: On the influence of the stratospheric quasi-biennial oscillation on the mesopause zonal wind over Central Europe, Meteorol. Zeitschrift, N. F., 5, 318-323, 1996.
Jarvis, M. J.: Latitudinal variation of quasi-biennial oscillation modulation of the semidiurnal tide in the lower thermosphere, J. Geophys. Res., 102, 27 177-27 187, 1997.

Keckhut, P., Hauchecorne, A., and Chanin, M. L.: Midlatitude longterm variability of the middle atmosphere: Trends and cyclic and episodic changes, J. Geophys. Res., 100, 18 887-18 897, 1995.

Kürschner, D., Schminder, R., Singer, W., and Bremer, J.: Ein neues Verfahren zur Realisierung absoluter Reflexionshöhenmessungen an Raumwellen amplitudenmodulierter Rundfunksender bei Schrägeinfall im Langwellenbereich als Hilfsmittel zur Ableitung von Windprofilen in der oberen Mesopausenregion, Z. Meteorol., 37, 322-332, 1987.

Labitzke, K.: On the signal of the 11-year sunspot cycle in the stratosphere and its modulation by the quasi-biennial oscillation, J. Atmos. Solar-Terr. Phys., 66, 1151-1157, 2004.

Lastovicka, J. and Bremer, J.: An overview of long-term trends in the lower ionosphere below $120 \mathrm{~km}$, Surveys in Geophysics 25, 66-99, 2004.

Namboothiri, S. P., Meek, C. E., and Manson, A. H.: Variations of mean winds and solar tides in the mesosphere and lower thermosphere over scales ranging from 6 months to 11a. Saskatoon $52^{\circ} \mathrm{N}, 107^{\circ} \mathrm{W}, \mathrm{J}$. Atmos. Terr. Phys., 56, 1313-1325, 1994.

Naujokat, B.: An update of the observed quasi-biennial oscillation of the stratospheric winds over the tropics, J. Atmos. Sci., 43, 1873-1877, 1986.

Ramaswamy, V., Chanin, M.-L., Angell, J., Barnett, J., Gaffen, D., Gelman, M., Keckhut, P., Koshelkov, Y., Labitzke, K., Lin, J.-J. R., O’Neill, A., Nash, J., Randel, W., Rood, R., Shine, K., Shiotani, M., and Swinbank, R.: Stratospheric temperature trends: Observations and model simulations, Rev. Geophys., 39, 71-122, 2001.

Taubenheim, J., Berendorf, K., Krüger, W., and Entzian, G.: Height dependence of long-term trends in the middle atmosphere, EGS XIX General Assembly, Session ST3, Grenoble, 1994.

Ulich, T. and Turunen, E.: Evidence for long-term cooling of the upper atmosphere in ionosonde data, Geophys. Res. Lett., 24, 1103-1106, 1997.

Van Loon, H. and Labitzke, K.: Association between the 11-year solar cycle and the atmosphere, Part IV: The stratosphere, not grouped by the phase of the QBO, J. Clim., 8, 827-836, 1990.

Von Cossart, G. and Taubenheim, J.: Solar cycle and long-period variations of mesospheric temperatures, J. Atmos. Terr. Phys., 49, 303-307, 1987. 